목재 보존용 액상 접착제의 제조 및 물성 연구

- 젤라틴과 카라기난 합성 중심으로 -

\title{
A Study on the Manufacture and Physical Properties of Liquid Adhesive for Wood Preservation
}

\section{- Focusing on the Synthesis of Gelatin and Carrageenan -}

\author{
오승준 ${ }^{1}$, 한원식 ${ }^{1}$, 위광철,* \\ ${ }^{1}$ 한서대학교 문화재보존과학연구센터, ${ }^{2}$ 한서대학교 문화재보존학과 \\ Seung Jun $\mathrm{Oh}^{1}$, Won Sik Han ${ }^{1}$, Koang Chul $\mathrm{Wi}^{2, *}$ \\ ${ }^{1}$ The Research Center of Conservation Science for Cultural Heritage, Hanseo University, Seosan 31962, Korea \\ ${ }^{2}$ Department of Cultural Heritage Conservation, Hanseo University, Seosan 31962, Korea
}

Received November 9, 2021

Revised December 1, 2021

Accepted December 7, 2021

*Corresponding author

E-mail: kcwi@hanseo.ac.kr

Phone: +82-41-660-1043

Journal of Conservation Science 2021;37(6):801-806

https://doi.org/10.12654/JCS.2021. 37.6.17

pISSN: 1225-5459, eISSN: 2287-9781

(c) The Korean Society of Conservation Science for Cultural Heritage

This is an Open-Access article distributed under the terms of the Creative Commons Attribution Non-Commercial License (http://creativecommons.org/ licenses/by-nc/3.0) which permits unrestricted non-commercial use, distribution, and reproduction in any medium, provided the original work is properly cited.

\begin{abstract}
초 록 전통 접착 소재인 아교의 사용성과 해초 추출물 카라기난의 겔화 현상을 개선하기 위해 두 재료를 혼합하여 목재 보존용 액상형 접착제를 제조하였으며, 9 종의 천연 및 합성 접착제와 의 물성 비교를 통해 적용 가능성을 확인하였다. 제조한 목재 접착제는 $15 \mathrm{wt} \%$ 아교 수용액과 $\lambda$-carrageenan, 항균제, 소포제 등을 혼합하였으며, $1.80 \mathrm{Mpa}$ 의 최대 접착 강도를 확인하였다. 비교 결과 5 종의 전통 천연 접착 성분(수용액)과 Polyvinyl acetate 기반 접착제 1종보다 우수한 접착 강도가 나타났으며, 총호기성생성균수와 유해성(TVOC, $\mathrm{HCHO}$, 중금속) 시험 결과 불검출 로 항균성과 안정성을 확인하였다.
\end{abstract}

중심어 목재 접착제, 젤라틴, 아교, 해초, 카라기난, 보존 재료

ABSTRACT In order to improve the usability of glue, a traditional adhesive material, and the gelation process of seaweed extract carrageenan, a liquid adhesive for wood preservation was prepared by mixing the two materials. The prepared wood adhesive was mixed with a $15 \mathrm{wt} \%$ aqueous solution of glue, $\lambda$-carrageenan, an antibacterial agent, an antifoaming agent, and the maximum adhesive strength of $1.80 \mathrm{Mpa}$ was confirmed. As a result of comparison, the adhesive strength was superior to that of 5 different types of traditional natural adhesive ingredients (aqueous solution) and 1 type of polyvinyl acetate-based adhesive.

Key Words Wood glue, Gelatin, Glue, Seaweed, Carrageenan, Conservation material

\section{1. 서 론}

고문헌에 나타나는 접착제는 크게 동물성 접착제와 식 물성 접착제로 나눌 수 있는데 동물성 접착제의 경우 동 물의 뼈와 가죽에서 추출한 아교(阿胗)와 어류의 껍질과 부레를 원료로 하는 어교(魚胗)가 있으며( $\mathrm{Wi}, 2021)$, 주로 민어의 부레를 이용하여 부레풀이라고도 한다. 식물성 접
착제의 경우 쌀, 밀가루, 감자, 옥수수 등의 전분을 사용하 는 녹말풀과 옻, 송진 등과 같은 목재 추출물, 해조 식물 인 도박과 우뭇가사리, 파해(까막과 청조류), 김, 미역, 톳 (갈조류)을 이용한 접착 성분이 있다(Oh et al., 2020).

아교의 기록은 명확하지 않지만「일본서기」는 610년 종이, 먹의 제조법을 전했다는 기록이 있어 삼국시대에 아교를 혼합할 수 있는 제조기술을 가지고 있었던 것으로 
추정된다. 이후 1715년 홍만선이 작성한 산림경제(山林經 濟)에는 중국의 거가필용을 인용한 아교 제조 방법이 자 세하게 기술되어 있고, 1834 년 이규경에 의해 기술된 오 주서종박물고변(五洲書種博物考辨)에서는 소가죽을 원 료로 하는 아교의 제조방법이 나타나 있다. 또한「경국대 전」과「조선왕조실록」등에서는 나무나 자개를 붙여 공 예품을 제작하고 어교(부레풀)와 아교를 혼합하여 활이 나 군수품 제작에 사용되었음을 알 수 있다(Encyclopedia of Korean Culture, 2019). 또 전주장이나 통영장 등의 전통 목가구를 제작하는 데 있어서도 접착 재료로 아교와 부레 풀 어교를 반씩 섞어 사용하여 강한 접착도를 유지시키고 있어 목가구 및 고정 건축재의 접착 재료로 일반적으로 사용되어 왔음을 알 수 있다(So, 2016).

그러나 아교는 접착력이 우수하고, 건조 중에 위치 및 접착 보정이 가능한 장점을 갖고, 통상 고체상으로 존재 하여 보관 및 취급이 간편하기는 하나(Kwon et al., 2003), 이를 접착제로 사용하기 위해서는 중탕하여 녹이고, 접착 력 및 점도 조절을 위해 물을 섞어서 사용하여야 하는 등 의 편리성이 떨어진다는 단점이 있다. 특히, 아교는 아교 의 원료 및 제조방법 등에 따라 그 종류가 매우 다양하고, 그 농도에 따라 상이한 접착력을 나타내는 등 최선 또는 최적의 접착력을 발휘하기 위해서는 많은 경험에 따른 농 도 조절 등이 요구되어 사용이 어렵다는 단점이 있다(Wi et al., 2019).

해초풀은 홍조류인 도박, 우뭇가사리 등과 갈조류인 다시마, 미역, 대황 등이 있는데 그 가운데 접착력이 좋은 것은 홍조류인 도박과 우뭇가사리이며, 특히 도박은 당을 많이 함유하고 있어 접착력이 가장 좋아서 풀을 만드는 데 주로 쓰는 해초류이다(Oh et al., 2019). 해초풀은 채취 해 물에 씻고 햇볕에 말리고 두들겨주고 다시 건조 후 5 6시간 정도 약한 불에 끓여 사용하였으며, 바랜 정도에 따라 색의 정도가 다르며, 하얗게 되면 풀을 쒀서 찌꺼기 는 걸러내고 사용하였다.

이렇게 만들어진 해초풀은 예로부터 주로 명주나 비단 을 풀할 때 또는 한지를 만들 때 닥풀 대용으로 사용하기 도 한다. 또한 문화재 보존에 있어 해초풀은 안료의 박락 방지용으로 사용되는데 처리 후 광택이나 얼룩을 남기지 않으며, 약 $1 \%$ 정도의 저 농도라도 상당한 점조성이 있어 접착성이 있기 때문에 안료층의 두께가 얇을 경우 광택이 나 얼룩을 거의 생기게 하지 않고 접착할 수 있는 장점이 있다. 뿐만 아니라 물에 잘 녹고 투명 균일한 용약이 되어 직물조직의 심부까지 잘 침투하여 옷감에 탄성을 주며 오 염방지와 세척성도 향상되고, 문화재수리에 이용되고 있 는 문화재수리표준품셈 및 표준시방서의 미장공사 항목
에서 해초풀을 섞어 사용하도록 명시하고 있다.

그러나 재료의 종류 및 산지, 채취일 등에 따라 특성이 다르고 건조와 탈염과정 및 끓이는 시간 등 제작자와 방 법에 따라 접착제의 균일함이 떨어질 수 있다. 또한 부패 방지를 위해 해초풀을 끓인 후 1 일 이상 두고 사용할 경 우에 석회가루를 뿌려주어야 하며, 이마저도 임시방편에 불가하여 사용상에 어려움이 따른다. 또한, 해초 추출물 중 카라기난의 경우, 사용성이 뛰어나고 그 응용성이 있 으며, 종이에 대한 접착력은 매우 강하게 나타나나, 목재 에의 적용 시에는, 특히 접착력의 부족으로 인하여 목재 접착용으로 사용하기 어렵다는 단점이 있다.

이에 본 연구에서는 아교의 사용성 개선과 동시에 카 라기난의 겔화 현상 및 접착력 증진을 위해 아교와 카라 기난을 배합하여 상호 단점을 보완한 새로운 접착제 개발 을 시도하였다. 이를 이용하여 아교의 수용화 이후 부패 의 문제와 시간이 지남에 따라 나타나는 점도 증가 현상 을 없애면서 안정한 접착 강도를 유지하는 접착제를 제조 하고자 하였다. 또 이들 재료의 최적 배합 조건을 연구하 여, 우수한 접착성과 친환경성 그리고 작업성(발림성)까 지 두루 갖춘 새로운 목재 접착제를 개발하고 이의 활용 가능성을 확인해보고자 한다.

\section{2. 재료 및 방법}

\section{1. 시약 및 기기}

Carrageenan은 국내산 홍조류 도박을 $\mathrm{K}_{2} \mathrm{CO}_{3}$ 용액 내에 서 가열한 후 에틸알코올 침강법을 이용하여 직접 추출하 여 분리 정제한 $\lambda$-carrageenan을 사용하였으며(Han et al., 2018) 용해도 조절과 풀림성 향상을 위해 사용한 Dextrin 은 삼정화학 $(\mathrm{KOR})$ 의 제품을 사용하였다. 점도 조절 및 접 착 보조제로 사용된 Polyvinylpyrrolidone $120\left(\mathrm{PVP}-120 / \mathrm{M}_{\mathrm{w}}\right.$ $1,300,000)$ 은 Yuanye사의 제품을 사용하였으며 소포제 $\mathrm{FD} 330 \mathrm{~A}$ 는 새한실리켐(KOR)의 제품을 사용하였다. 사용 된 방부제는 두 종류로 ethylhexylglycerine(EHG)과 2-phenoxyethanol(POE)이었으며 각각 신승하이켐(KOR) 의 제품과 삼전화학 $(\mathrm{KOR})$ 의 제품을 사용하였다. 첨가되 는 $\mathrm{EHG}$ 와 $\mathrm{POE}, \mathrm{FD} 330 \mathrm{~A}$ 는 식품과 화장품에 첨가되는 제 품으로 원하는 소포성과 항균성을 가질 수 있는 최소량을 찾아 첨가하였다. 아교는 Nakagawaho-gofun사(JPN)의 아 교(播州粒膠)를 사용하였으며 나머지 접착제 제조에 사 용된 재료들은 모두 분석급의 시약을 사용하였다.

제조된 목재 접착제의 비교 물성을 확인하기 위해 상 용의 천연 및 합성 접착제 9종을 선정하여 접착 강도를 
확인하였다. 천연 접착제들은 모두 $15 \mathrm{wt} \%$ 수용액으로 제조한 5 종(아교, 토끼교, 감자 전분 풀, 소맥전분 풀, 카 라기난)과 시판용 목재 합성 접착제 중 polyvinyl acetate 기반 접착제 3종(이하 $\mathrm{M}, \mathrm{D}, \mathrm{A}$ 접착제), $\mathrm{PVA}$ 기반 접착제 (이하 P 접착제) 1 종을 대상으로 하였으며, 합성 접착제는 별도의 전처리 과정을 거치지 않고 실험하였다.

만능재료시험기는 일본 Shimadzu사의 AG-X plus $5 \mathrm{kN}$ model을 사용하였으며 유해성 평가에는 ICP mass는 PerkinElmer사(USA)의 Nexion 2000B 모델과 OES Optima 8300 모델, HPLC A-10altus 모델, Clarus 600 모델, Agilent 사(USA)의 GC-mass 7890B 모델을 이용하여 카드뮴(LoQ $1.0 \mu \mathrm{g} / \mathrm{g})$, 납(LoQ $2.0 \mu \mathrm{g} / \mathrm{g})$, 크로뮴(LoQ $2.5 \mu \mathrm{g} / \mathrm{g})$, 에틸벤 젠 $\left(\mathrm{LoD} 2.5 \times 10^{-4} \%\right)$, 자일렌 $\left(\mathrm{LoD} 6.0 \times 10^{-4} \%\right)$, 포름알데 하이드 $(\mathrm{LoQ} 40.0 \mu \mathrm{g} / \mathrm{g})$, 벤젠 $\left(\mathrm{LoD} 2.0 \times 10^{-5} \%\right)$, 톨루엔 $\left(\mathrm{LoD} 2.0 \times 10^{-5} \%\right)$ 의 함유량을 분석하였다.

\section{2. 접착제 제조}

목재용 접착제는 아교 수용액과 카라기난 수용액을 함 께 혼합할 수 있는 reflux condenser와 온도 조절 센서, 회 전용 임펠라가 삽입될 수 있는 3 구 분리 반응 초자에서 $90^{\circ} \mathrm{C}$ 에서 가열하여 제조하였다. 아교와 $\lambda$-carrageenan을 이용한 목재 접착제는 봉황 아교 용액과 $\lambda$-carrageenan 수 용액을 따로 준비하고 이들을 혼합하는 방법으로 제조하 였다. 아교 수용액은 5.0 30.0\%의 함량이 되도록 제조하 였으며 제조된 아교 수용액 $50 \mathrm{~g}$ 의 온도를 $80^{\circ} \mathrm{C}$ 로 낮추었 다. dextrin $0.20 \sim 0.38 \mathrm{~g}$, 카라기난 $1.60 \sim 3.42 \mathrm{~g}$, PVP $2.0 \sim$ $3.8 \mathrm{~g}$ 를 증류수에 용해시킨 $50 \mathrm{~g}$ 의 수용액에 $0.1 \mathrm{~g}$ 의 소포 제를 첨가하여 제조한 $\lambda$-carrageenan 수용액을 $80^{\circ} \mathrm{C}$ 의 아 교 수용액과 혼합하여 교반하면서 1 시간 동안 가열하였 다. 화원을 제거하고 바로 전체 용량의 $0.5 \%$ 에 해당하는 양의 $\mathrm{EHG}$ 와 $0.2 \%$ 에 해당하는 $\mathrm{POE}$ 를 첨가하여 용액이 균 일해질 때까지 교반한 후 밀봉하였으며 안정화를 위하여 상온에서 48시간 이상 유지시킨 후 사용하였다.

\section{3. 인장 전단 접착 강도 및 항균성 평가}

인장 전단 접착 강도는 KS M 3720(접착제의 목재 인장 전단 접착강도 시험 방법)에 준하여 측정하였으며, 목재 시편 겹치는 부위에 $0.3 \mathrm{~g}$ 의 제조된 접착제를 도포한 후 상온에서 클램프를 이용해 고정하여 24시간 건조하여 만 능재료시험기에서 $2 \mathrm{~mm} / \mathrm{min}$ 의 인장 속도로 측정하였다. 총 샘플의 수는 10 개였으며 최고치와 최저치를 제외한 결 과의 평균값을 기록하였다.
항균성 평가는 총호기성생균수 시험으로 진행하였으 며, 직경 $9 \mathrm{~cm}$ 페트리 접시에 굳힌 변형 레틴 한천 배지 표면에 검액 $1.0 \mathrm{~mL}$ 를 도포하였다. 이를 $35^{\circ} \mathrm{C}$ 에서 48 시간 배양하였으며, 총세균수를 측정하였다.

\section{3. 결과 및 고찰}

목재 접착제 제조 중 소포성은 주로 카나기난 용액의 제조 과정에서 필요한 것으로 $0.18 \%$ 미만 사용 시 일부 미세한 기포들이 제조 과정에서 남게 되어 $0.20 \%$ 를 사용 하였다. 접착제 내의 기포의 유무는 접착제 물성에는 큰 차이를 나타내지를 않지만 기포 발생으로 인한 혼합도의 문제와 미관의 문제, 미세 기포들로 기인한 접착제의 추 후 내부 건조 문제들을 고려하여 최소량의 첨가를 결정하 였다.

아교 용액의 경우, 농도를 $5 \%$ 에서 $30 \%$ 까지 조정하면 서 접착강도를 측정한 결과, $15 \%$ 까지는 아교 농도 증가 에 따라 접착 강도가 급격하게 증가하였으나, $15 \%$ 이후 에는 접착 강도가 완만한 증가하는 경향을 보였다. 아교 농도 $10 \%$ 수용액을 사용하였을 때 혼합성과 제조 과정에 서 우수하였으나 많은 희석으로 아교 본래의 접착성(< $0.7 \mathrm{MPa}$ )을 나타내기 힘들었으며 또 $20 \%$ 가 넘어가게 되 면 접착성은 증가하나 추후 혼합 용액 제조 시에 하층부 에서 $\lambda$-carrageenan 용액과 충분치 못한 혼합의 문제가 생 기고 실온화 후 점도가 비이상적으로 증가하여 사용성에 문제를 나타내었다. 이와 같이 접착성과 제조 과정, 실온 화 후 점도들을 고려하였을 때 아교 농도는 $20 \%$ 이하로 조절하는 것이 합당하나, 아교 농도 $15 \sim 20 \%$ 사이에서는 접착 강도의 차이가 미미하므로 카라기난과의 혼합액 제 조 시에 혼합이 보다 편리한 $15.0 \%$ 를 아교 수용액의 농도 로 선정하여 진행하였다(Figure 1).

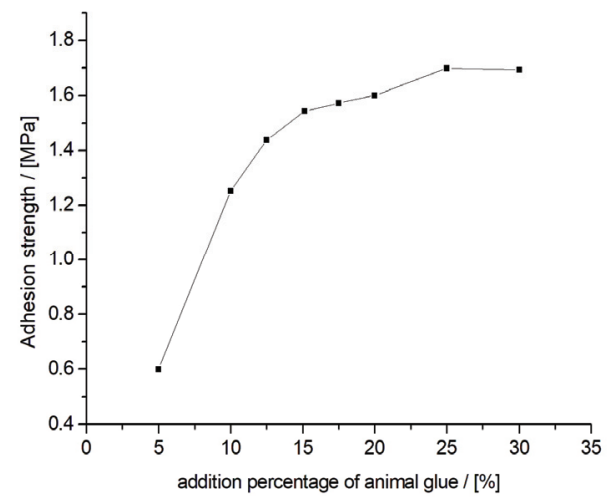

Figure 1. Changes in adhesive tensile strength of animal glue solution. 
$50 \mathrm{~g}$ 의 $15 \%$ 아교 수용액에 혼합될 $50 \mathrm{~g}$ 의 $\lambda$ -carrageenan 수용액은 PVP량을 $2.8 \mathrm{~g}$ 으로 고정하고 $\lambda$ -carrageenan의 사용량을 변화시켰을 때, $2.8 \mathrm{~g}$ 의 $\lambda$ -carrageenan 함량에서 가장 높은 $1.80 \mathrm{Mpa}$ 접착 강도를 나타냄을 확인할 수 있었다. $\lambda$-carrageenan의 사용량이 3.0 $\mathrm{g}$ 을 초과하면, 접착 강도의 저하도 발생하지만 고점도화 로 인하여 사용상의 문제가 나타나서 접착제로서의 특성 을 나타내지 못하는 것으로 판단되었다(Figure 2). 또 PVP 의 사용량을 $2.4 \mathrm{~g}$ 으로 고정시키고, $\lambda$-carrageenan의 사용 량을 변화시켰을 때, 최고 접착 강도는 $1.55 \mathrm{Mpa}$ 였으나 이 역시도 $\lambda$-carrageenan의 사용량이 $2.6 \mathrm{~g}$ 을 초과하면, 점 도 증가로 인하여 접착제로서의 사용 불가능하였다 (Figure 3). PVP의 사용량을 $3.2 \mathrm{~g}$ 으로 증가시키고, $\lambda$ -carrageenan의 사용량을 변화시켰을 때, 최고 접착 강도 가 $1.60 \mathrm{Mpa}$ 를 나타내었으나 여기에 $\lambda$-carrageenan의 사용 량을 증가시켜도 접착 강도가 증가되는 결과를 나타내지 않는 것으로 보아 PVP가 일정 부분 접착에 관여하지만

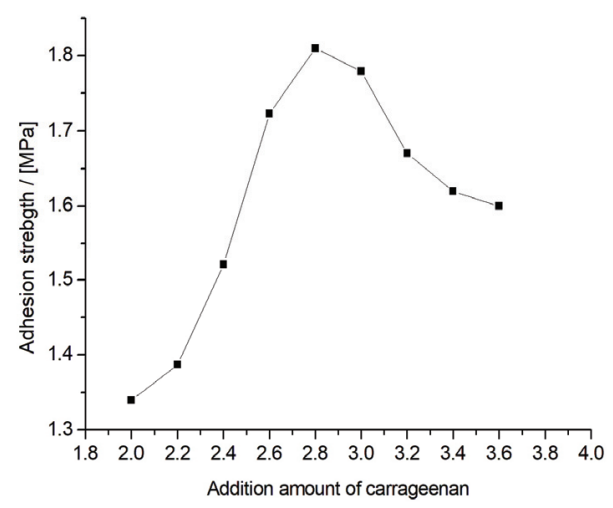

Figure 2. Adhesive strength change according to the amount of $\lambda$-carrageenan used (PVP $2.8 \mathrm{~g}$ ).

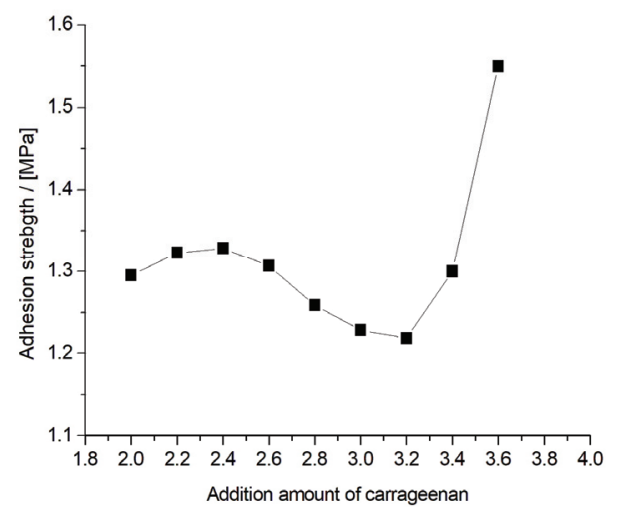

Figure 3. Adhesive strength change according to the amount of $\lambda$-carrageenan used (PVP $2.4 \mathrm{~g}$ ).
목재 접착에 적용할 만큼 접착도가 증가하는 인자는 아닌 것으로 볼 수 있었으며, 첨가된 PVP는 접착 보조와 점도 저하제로의 역할을 주로 하게 되는 결과를 나타내었다.

항균제는 전체 함량의 $\mathrm{EHG}$ 를 단독으로 사용 시 $1.3 \%$ 이상의 $\mathrm{EHG}$ 가 첨가되어야 호기성균이 검출되지 않았으 나 이 사용량을 줄이기 위하여 POE $0.2 \%$ 를 함께 첨가하 여 EHG 사용량을 총량의 $0.5 \%$ 로 낮추어 제조하였다. 이 두 종류의 방부제는 화장품 첨가제로서의 안전성이 비슷 하여 총사용량이 $40 \%$ 이상 감소할 수 있었으며 이 경우 에 총호기성 생균수 배양 결과가 $1.3 \%$ 이상의 $\mathrm{EHG}$ 가 첨 가되어야 나타나는 결과와 같이 $0 \mathrm{cfu} / \mathrm{g}$ 의 결과를 나타내 고 있어서 두 항균제의 혼합 사용이 최소의 항균제 사용 의 역할을 하게 되는 것으로 판단할 수 있었다.

이렇게 제조된 목재 접착제는 밀폐 시 6개월 이상 물성 의 변화나 표면의 고화 문제, 균주로 인한 부패나 색변 등이 나타나지 않았으며 벤젠, 톨루엔, 에틸벤젠, 자일렌 등의 TVOC와 $\mathrm{HCHO}$ 및 납, 카드뮴, 크로뮴 등의 중금속 들도 모두 불검출을 확인할 수 있어서 환경 친화적 접착 제로 볼 수 있었다.

전체적으로 볼 때, $15 \%$ 아교 수용액 $50 \mathrm{~g}$ 과 PVP 2.8 $\mathrm{g}$ 과 $\lambda$-carrageenan $2.8 \mathrm{~g}$ 가 포함된 $50 \mathrm{~g}$ 의 $\lambda$-carrageenan 수 용액 두 가지를 혼합한 접착제가 가장 우수한 접착 강도 를 나타냄을 확인할 수 있었다. 이는 아교만을 이용한 수 용액의 접착 강도를 $\lambda$-carrageenan이 첨가되어 접착 강도 가 향상된 결과를 나타내었으며 아교 수용액 단독 사용으 로 인한 부패 현상과 단독 사용 시 나타나는 점도 변화 등의 문제를 해결하고 사용성을 향상시킨 변형 아교 접착 제 제조 결과로 볼 수 있었다. 아교만을 이용한 수용성 접착제의 경우, $\mathrm{EHG}$ 와 $\mathrm{POE}$ 의 첨가로 인하여 부패 현상 을 해결할 수는 있으나 일부 방사선 처리한다 하여도 점 도의 변화가 나타나서 사용성의 문제를 나타내는 반면에 본 혼합 접착제의 경우, 접착도 및 점도의 변화가 없이 항변성 접착 능을 나타내고 있었다. 이러한 결과를 바탕 으로 목재 보존용 액상 접착제의 최종 조성은 Table 1과 같다.

최종 조성으로 합성된 액상형 목재 접착제와 전통 천 연 소재 접착제 및 합성 접착제의 비교 접착 강도 결과는 Table 2 와 같다. 천연 접착제의 경우 목재 접착제 제조 시 사용한 아교 수용액과 동일한 조건인 $15 \mathrm{wt} \%$ 수용액을 제조하여 측정하였으며, 측정 결과 $15 \mathrm{wt} \%$ 감자 전분 풀 $(0.12 \mathrm{Mpa})$ 과 $15 \mathrm{wt} \%$ 밀가루 전분 풀 $(0.15 \mathrm{Mpa})$ 은 카라기 난과 아교 수용액에 비해 낮은 접착 강도를 나타내었으 며, $1.10 \mathrm{Mpa}$ 의 토끼교는 천연 접착제 중 가장 높은 결과 를 확인하였으나 본 연구에서 제조한 목재 접착제보다는 
Table 1. Composition of wood adhesive

\begin{tabular}{|c|c|c|c|c|c|}
\hline \multicolumn{6}{|c|}{ Total ratio } \\
\hline $\begin{array}{c}\text { Animal glue } \\
\text { aqueous solution } \\
\text { (animal glue } 15 \text { wt } \% \text { ) }\end{array}$ & $\begin{array}{c}\lambda \text {-carrageenan } \\
\text { (in Dextrine } 10 \% \text { ) }\end{array}$ & PVP & EHG & POE & FD330A \\
\hline $50 \mathrm{~g}$ & 2.8 & 2.8 & 0.5 & 0.2 & 0.2 \\
\hline
\end{tabular}

Table 2. Result of comparative physical property test

\begin{tabular}{|c|c|c|c|c|c|c|c|c|c|c|}
\hline \multirow{3}{*}{ Adhesiv } & \multicolumn{5}{|c|}{ Natural adhesiv } & \multicolumn{4}{|c|}{ Synthetic adhesiv } & \multirow{3}{*}{$\begin{array}{c}\begin{array}{r}\text { Wood } \\
\text { adhesiv }\end{array} \\
\\
1.80\end{array}$} \\
\hline & $\begin{array}{l}\text { Potato starch } \\
\text { adhesive }\end{array}$ & Animal glue & Hare glue & $\begin{array}{c}\text { Wheat starch } \\
\text { adhesive }\end{array}$ & $\begin{array}{c}\lambda \text {-carrageenan } \\
\text { adhesive }\end{array}$ & \multirow[t]{2}{*}{$\mathbf{M}$} & \multirow[t]{2}{*}{ D } & \multirow[t]{2}{*}{$\mathbf{P}$} & \multirow{2}{*}{$\mathbf{A}$} & \\
\hline & \multicolumn{5}{|c|}{ (Aqueous solution 15 wt\%) } & & & & & \\
\hline $\begin{array}{c}\text { Adhesion } \\
\text { (Mpa) }\end{array}$ & 0.12 & 0.17 & 1.10 & 0.15 & 0.16 & 3.77 & 1.75 & 3.41 & 3.76 & \\
\hline
\end{tabular}

낮은 결과를 확인하였다. 이러한 결과는 접착성분의 혼합 농도에 따라 증감이 있겠으나 실제 사용 시 처리자 또는 작업자에 따라 농도를 조절하여 사용하는 특성에 맞춰볼 때 목재 접착제로서의 충분한 접착 강도를 확보한 것으로 판단된다. 또한 시판용 합성 접착제는 Polyvinyl acetate 기 반 접착제인 $\mathrm{D}$ 접착제는 개발 접착제보다 낮은 접착 강도 를 나타내었으며, 다른 3종의 합성 접착제는 $\mathrm{M}$ 접착제 $3.77 \mathrm{Mpa}, \mathrm{P}$ 접착제 $3.41 \mathrm{Mpa}, \mathrm{A}$ 접착제 $3.76 \mathrm{Mpa}$ 로 제조 한 목재 접착제보다 높은 접착 강도를 확인하였다. 이는 개발 접착제가 합성 접착제보다는 다소 낮으나, 기존 천 연 접착제에 비해 우수한 접착 강도를 가지는 것을 보여 주는 결과였으며 또한 개발 접착제는 친환경성과 항균성 까지 갖추고 있어 향후 시판 합성 접착제에 대한 대체 가 능성까지 엿볼 수 있는 결과로 사료된다.

\section{4. 결 론}

본 연구에서는 현재 목재를 이용해 제작된 목재 문화 재 또는 목공예품 등의 보존에 사용 가능한 천연 접착제 를 개발하기 위한 기초연구를 진행하였으며, 아교의 젤라 틴 성분과 도박의 carrageenan 성분을 혼합해 최적의 합성 조건을 찾아 액상형 목재 접착제를 제조하고 물성 및 안 정성 테스트를 진행하였다.

이 접착제는 아교의 사용성 증진을 위하여 수용화할 경우 나타나는 부패 현상, 고점도로 인한 사용성의 문제 등을 해결한 항변성 접착제로 $50 \mathrm{~g}$ 의 $15 \%$ 아교 수용액과 $\lambda$-carrageenan $2.8 \mathrm{~g}$ 과 PVP가 $2.8 \mathrm{~g}$ 이 포함된 $50 \mathrm{~g}$ 의 $\lambda$ -carrageenan 수용액에 식품용 혹은 화장품용 소포제와 항 균제가 소량 첨가하여 제조되었다. 이들의 최고 접착 강 도은 $1.80 \mathrm{Mpa}$ 로 아교 수용액 단독으로 사용했을 때보다 증진된 접착 강도를 나타내고 있었으며, 기존에 사용되어 온 전통 천연 소재 접착제를 상회하는 접착 강도를 확인 하여 적용 가능성을 높였다.

또한 중금속이나 휘발성 유기화합물이 포함되지 않은 친환경 목재 접착제로 제조되었으며 첨가제의 양을 극소 화하기 위하여 최소량의 소포제를 사용하였으며 항균제 도 두 가지를 사용하여 기존 항균제의 사용량을 $40 \%$ 이 상 감소하여도 호기성 균주의 배양을 없앨 수 있는 결과 를 나타내었다. 제조 후 밀폐 보관 시 6개월 이상 물성 변화와 부패 및 점도의 변화가 없는 것을 확인하여 전통 천연 접착제의 보관성을 개선하고 사용성이 편리한 친환 경 목재 접착제로 사용할 수 있을 것으로 볼 수 있었다.

다만 합성 접착제의 접착 강도 및 경제성, 사용성은 카 라기난 추출공정의 단순화와 안정적인 평활도, 점도 조절 에 다른 사용성 최적화, 아교와 카라기난의 배합 농도를 증가시킬 수 있는 조건에 대한 연구를 통해 개선되어야 할 것으로 판단되며, 본 연구가 시작점이 될 수 있을 것 이다.

\section{사 사}

본 논문은 2018년 문화기술연구개발(지정과제) 사업 (과제 번호 R2018020045)의 지원을 받아 연구되었으며, 이에 감사합니다. 


\section{REFERENCES}

Encyclopedia of Korean Culture, 2019, Woodcraft. http://encykorea.aks.ac.kr/ (November 1, 2019) (in Korean)

Han, W.S., Oh, S.J., Kim, Y.M., Lee, Y.J., Kim, Y.J., Park, M.S. and Wi, K.C., 2018, Base study related with development of natural bio-adhesives using seaweeds. Journal of Conservation Science, 34(6), 595-604. (in Korean with English abstract)

Kwon, S.O., Nam, C.K., Noh, E.H., Park, J.H., Shin, S.W., Lee, E.K. and Cho, S.H., 2003, Craft materials and techni-ques. Taehakwon, Seoul, 125-209. (in Korean)

Oh, S.J., Han, W.S. and Wi, K.C., 2019, Preparation of stick type solid glue as paper adhesive using mixed seaweed extract. Journal of Conservation Science, 35(4), 269-277. (in Korean with English abstract)

Oh, S.J., Han, W.S. and Wi, K.C., 2020, Carrageenan-based liquid bioadhesives for paper and their physical properties. Journal of Conservation Science, 36(6), 541-548. (in Korean with English abstract)

So, B.J., 2016, Chosun traditional furniture - a study on the restore of Jeonju-chest. Master's dissertation, Woosuk University, Wanju, 15-21.

Wi, K.C., 2021, Study on the manufacturing and applicability of natural glues for woodcrafts using shark skin. Journal of Korea TAPPI, 53(2), 15-23.

Wi, K.C., Oh, S.J., Han, W.S. and Park, M.S., 2019, A study on multiple bases for development of natural adhesives for wodcraft using celulose extracts from wood and their aplication potential: focused on salicis radicis cortex, hibiscus, Chinese wild peach resin. The Korean Society of Science \& Art, 37(5), 239-248. (in Korean with English abstract) 